\section{Effectiveness of an intervention focusing on diet and walking during pregnancy in the primary health care service}

\author{
A efetividade de uma intervenção na atenção \\ primária voltada para a dieta e caminhadas \\ durante a gravidez
}

\section{Efectividad de una intervención centrada en la dieta y paseos durante la gestación en el servicio de atención primaria en salud}

\author{
Maíra Barreto Malta 1,2 \\ Caroline de Barros Gomes 3 \\ Aluísio J. D. Barros 4 \\ Larissa Gastraldi Baraldi 5 \\ Monica Yuri Takito 6 \\ Maria Helena D’Aquino Benício 1 \\ Maria Antonieta de Barros Leite Carvalhaes 3
}

\begin{abstract}
Interventions during prenatal care can mitigate negative outcomes of a sedentary lifestyle and unhealthy diet during pregnancy. We aimed to evaluate the effectiveness of an intervention that promoted healthy diet and leisure-time walking during antenatal care in a pragmatic, controlled, non-randomized intervention study. Physicians and nurses from all health care units of the Family Health Strategy model of health assistance participated in educational training to promote leisure-time walking and healthy diet during antenatal care visits. Pregnant women who received health care from these professionals constituted the intervention group $(n=181)$. The control group $(n=172)$ included pregnant women who received routine antenatal care, in health care units of the traditional model of health assistance. Data were collected in each trimester of pregnancy. Diet was investigated using a food frequency questionnaire adapted from Risk and Protective Factors Surveillance System for Chronic Non-Comunicable Diseases Through Telephone Interview (Vigitel). Leisure-time walking in a typical week was assessed using questions from the Physical Activity in Pregnancy Questionnaire. There were positive effects on leisure-time walking during the second trimester and the third trimester of pregnancy and on the women who achieved 150 minutes per week of walking during the third trimester. The intervention reduced the risk of pregnant women consuming soft drinks and/or commercially prepared cookies in the third trimester. This lifestyle intervention was partially effective, tripling the proportion of pregnant women who achieved the recommended walking time and reducing by half the proportion of women who had a high weekly consumption of soft drinks and industrially processed cookies.
\end{abstract}

Pregnancy; Health Knowledge, Attitudes, Practices; Diet, Food, and Nutrition

\author{
Correspondence \\ C. B. Gomes \\ Faculdade de Medicina de Botucatu, Universidade Estadual \\ Paulista Júlio de Mesquita Filho. \\ Av. Prof. Montenegro s/n, Botucatu, SP 18618-687, Brasil. \\ carol.bgomes@yahoo.com.br \\ 1 Faculdade de Saúde Pública, Universidade de São Paulo, São \\ Paulo, Brasil. \\ 2 Programa de Pós-graduação em Saúde Coletiva, Universidade \\ Católica de Santos, Santos, Brasil. \\ 3 Faculdade de Medicina de Botucatu, Universidade Estadual \\ Paulista Júlio de Mesquita Filho, Botucatu, Brasil. \\ 4 Programa de Pós-graduação em Epidemiologia, Universidade \\ Federal de Pelotas, Pelotas, Brasil. \\ 5 Núcleo de Estudos e Pesquisas e Alimentação, Universidade \\ Estadual de Campinas, Campinas, Brasil. \\ ${ }^{6}$ Escola de Educação Física e Esporte, Universidade de São \\ Paulo, Brasil.
}




\section{Introduction}

Healthy diet and regular physical activity during pregnancy are protective factors against negative events such as macrosomia, gestational diabetes, future obesity for mother and child, among others 1,2,3,4. However, a sedentary lifestyle 5,6, a low intake of fruits and vegetables and a high intake of soft drinks and processed foods that are high in sugar and fat are frequently observed among pregnant women in Brazil 7,8 and in several developed countries 4,9. This situation has motivated the search for interventions that can modify it.

Studies that evaluate interventions in physical activity and diet together showed that the interventions reduced risks of weight gain and preeclampsia 10 . The physical activity intervention alone was associated with lower gestational weight gain, lower likelihood for gestational diabetes, and for delivery of a large-for-gestational-age infant ${ }^{2}$. Regarding behavioral changes in physical activity and diet, an intervention study on Chinese pregnant women showed that, after individualized guidance on physical activity and delivery of support material, the women spent less time resting and more time performing mild activity than women in the comparison group 11. Regarding diet, intervention counseling had a positive impact on energy, macronutrient, and fiber intake 12 . Another intervention increased fruit and vegetable intake and improved the overall dietary quality of participants 13 .

An important aspect of the studies is that most interventions in pregnancy are performed by a team of researchers and acting under strict supervision in ideal conditions and have been developed in the academic context. Only in a recent study conducted in Germany there was an intervention involving dietary and physical activity counseling in routine prenatal care 14 . Therefore, knowledge about the effectiveness of interventions in routine prenatal care is limited, particularly in middle/ low-income regions or countries. In countries such as Brazil, with antenatal care based on primary health care services, it is important that the interventions are simple to implement and do not involve additional structure, equipment and expenses to health services. Prenatal visits can be an opportunity to promote healthy diet and physical activity.

Thus, the objective of this study was to evaluate the effectiveness of an intervention that systematically promoted healthy diet and leisure-time physical activity during all antenatal care conducted by physicians and nurses of primary health care services during routine antenatal visits. The main hypothesis of the study was that an intervention administered during antenatal care could increase the percentage of pregnant women who achieved 150 minutes per week of leisure-time walking 15 and adhered to five dietary habits 16 (consumption of three fruits daily; two portions of vegetables daily; two portions of beans at least five days per week; and maximum of once per week consumption of soft drinks and commercially prepared cookies).

\section{Methods}

\section{Design and population}

This is a pragmatic, controlled, non-randomized intervention study with low-risk pregnant women (without diseases, such as diabetes, heart disease or hypertension) receiving public primary health care. The study was conducted in Botucatu, São Paulo State, a midsized city with approximately 130,000 inhabitants at the time of data collection and a predominantly urban population (93\%) located in southeastern Brazil 17.

To align the intervention with the current primary health care policy in Brazil 18, the pregnant women in the intervention group (IG) were recruited in the city's nine family health units (FHU), having been assisted by professionals who had previously participated in an educational activity aimed to increase their capacity to promote diet and physical activity during antenatal care. Each FHU assists approximately 1,000 families and includes a general physician, nurses, nursing technicians, dentists and community health agents 18 . Details about this educational intervention have been described by Malta et al. 19. The comparison group (CG) consisted of pregnant women who received antenatal care at eight traditional health units (THU), assisted by obstetricians and nurses who had not participated in educational activity. These pregnant women received routine antenatal care in accordance with 
national recommendations 20 , which does not include clarification about the benefits of physical activity on the fetus and on women's health. In addition, pregnant women are not advised about time, intensity and frequency of walking during leisure time.

It was not feasible to randomize the pregnant women into groups (intervention and control) because it was not possible to prevent interactions among pregnant women and among health professionals, since the health professionals from the same type of health units (FHU or THU) have monthly meetings where they exchange experiences, share knowledge and solve administrative issues, and all pregnant women wait in the same room in the health unit prior to being served. Thus, it would be impossible to randomly select the intervention and control units because there would be contamination of the intervention, especially as to the aspects addressed in training or educational action.

From November 2012 to June 2013, all pregnant women $(n=362)$ enrolled in the 17 antenatal public health units in the urban area of Botucatu, aged 18 years or more and in the first gestational trimester were invited to participate in the study. Pregnant women who moved to antenatal care in private health services during the follow-up, moved to another city, suffered abortion, presented conditions that classified them as having high-risk pregnancies 21 or had any adverse condition that required rest or reduced physical activity 15 were excluded.

We calculated the minimum sample size needed to detect differences in the proportions of pregnant women who achieved the recommended leisure-time walking in the third trimester of $5 \%$ to $15 \%$, with a significance level of $5 \%$ and a power of $80 \%$. Furthermore, we added $15 \%$ for multiple statistical analysis and $10 \%$ for possible losses to follow-up. The resulting minimum sample size was 280 patients (140 in each group); this sample also enabled us to detect changes in diet of 40 to $50 \%$, which are relevant in the context investigated.

\section{Intervention}

The intervention was divided into two main components:

(1) Training all of physicians and nurses responsible for antenatal care in family health units through an educational activity that lasted 16 hours and consisted of an immersion course and three workshops. This training aimed to update, standardize and expand the professionals' knowledge of diet and physical activity during pregnancy and help them promote these behaviors in antenatal care in a systematic manner. In addition, to support the professionals' promotion of these behaviors, the following educational materials were developed: a form with key information about diet and physical activity to visually support the conversation between the professionals and pregnant women; a folder to be provided to pregnant women and posters containing messages encouraging the adoption of the promoted behaviors; an assessment of gestational weight gain; and a record of the guidelines on diet and physical activity provided to pregnant women. These materials are available at: https:// repositorio.unesp.br/handle/11449/139304. These health professionals were trained to use the transtheoretical model of health behavior change in all antenatal consultations 22 and the techniques of motivational interviewing 23 to promote healthy practices regarding diet and physical activity. Thus, the consultation time dedicated to these actions was tailored by the professional.

(2) Systematic promotion of diet and physical activity during antenatal visits. The pregnant women were counseled individually about the importance and benefits of 5 healthy dietary habits and were motivated to adopt these habits: consumption of 3 fruits daily; 2 portions of vegetables (one raw and one cooked) and 2 portions of beans (one at lunch and one at dinner) at least 5 days per week; and sporadic consumption of soft drinks and commercially prepared cookies. The selection of these 5 dietary habits was based on previous studies conducted in the same municipality 6,24,25. These recommendations were based on national guidance concerning diet during pregnancy 16 and in the national food guide 26 . In addition, the women were informed of the importance of physical activity and its benefits to the developing fetus and to their own health. Specifically, they were encouraged to engage in leisure-time walking five times per week or more for 30 to 40 minutes each and at moderate intensity. According to current international guidelines, for pregnant women to be considered active and therefore experience the resulting benefits, they must engage in a minimum of 150 minutes of moderate or vigorous physical activity per week 15 . Of note, previously inactive pregnant women were 
instructed to start walking for a shorter period and with lower intensity and to progressively increase their activity to reach the recommendation 15,27 .

Considering the ecological model adapted from Bauman et al. 28 and Giles-Corti 29 , the intervention focused on intra and interpersonal factors that act on behavioral changes (Figure 1).

\section{Data collection}

The recruitment of pregnant women occurred in public health units, when they registered for antenatal care and scheduled the first visit. After agreeing to participate in the study, data collection was conducted at the participants' home by four trained interviewers. These interviewers had no connection with the health professionals who conducted the intervention. The follow-up ended in February 2014.

The first interview occurred prior to the first antenatal visit. During the interview, the following data were collected: (a) socioeconomic and demographic data: maternal age (18-19, 20-30, or $\geq 30$ ), maternal occupation (unpaid job or paid job), cohabiting with a partner (yes or no), maternal education ( $<8$ or $\geq 8$ years), socioeconomic position (class B, class C, or classes D/E - Brazilian Association of Research Companies - ABEP. Critério de Classificação Econômica Brasil. http://www.abep.org/, accessed on 10/May/2015), self-reported maternal skin color (white, black, brown, indigenous, or yellow, as defined by the Brazilian Demographic Census of the Brazilian Institute of Geography and Statistics); (b) obstetric data: primigravida (yes or no), gestational age (in weeks); (c) pre-pregnancy lifestyle: tobacco use (yes or no), alcohol intake (yes or no), diet (intake of fruits, vegetable, beans, soft drinks and/or commercially prepared cookies) and leisure-time walking (yes or no; achieves 150

\section{Figure 1}

Theoretical framework of the intervention on diet and physical activity among pregnant women. Botucatu, São Paulo State, Brazil, $2012-2014$.

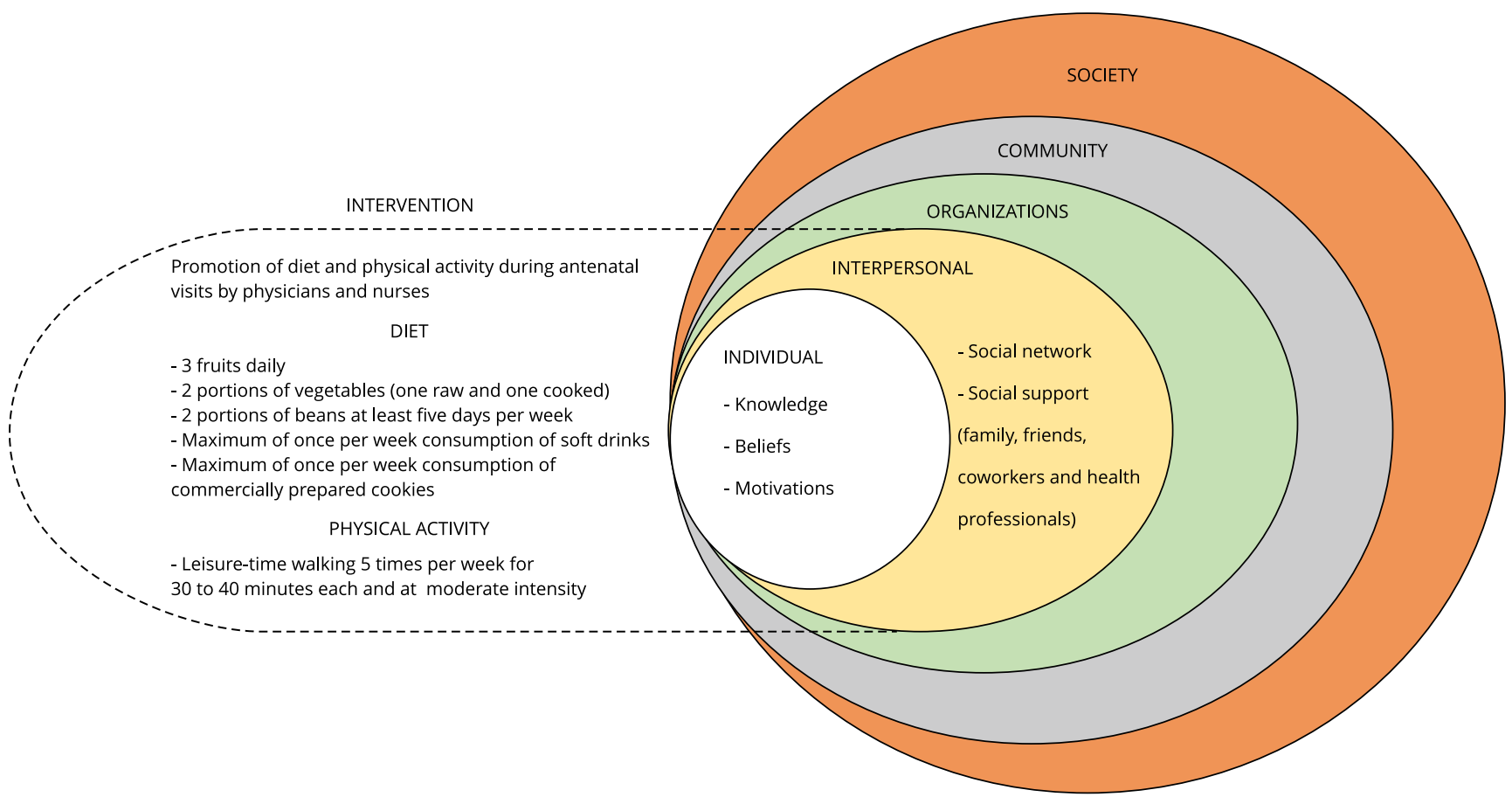

Source: adapted from Giles-Corti et al. 29 and Bauman et al. 28. 
minutes per week). The socioeconomic position was evaluated according to the classification criteria of the ABEP, considering the family's ownership of assets and the educational level of the head of the household, which is divided into economic classes A (highest), B, C, D and E (lowest). We evaluated, through observation, certain factors in the environment, including the presence or absence and quality of street paving, sidewalks, and street lighting, to determine whether the place near the pregnant woman's residence was suitable for walking. This was defined as a dichotomous variable, favorable environment for walking (presence of all items) and unfavorable environment for walking (absence of one or more). The pregnant women's weight and height were collected from medical records to calculate their pre-pregnancy body mass index (BMI).

Diet and physical activity data were collected in each trimester of pregnancy: in the first trimester, referring to three months prior to pregnancy; in the second and third trimesters, referring to the week prior to the interview. Regarding diet, the frequency and number of typically consumed portions of fruits, vegetables, beans, soft drinks and commercially prepared cookies were investigated using a questionnaire adapted from that used by Vigitel (Risk and Protective Factors Surveillance System for Chronic Non-Comunicable Diseases Through Telephone Interview) and validated in Brazil 30. Concerning the practice of physical activity, we applied the following questions from the Physical Activity in Pregnancy Questionnaire (PPAQ) 31: "Did you walk for fun or exercise? How many days of the week did you walk for fun or exercise? How much time did you spend walking for fun or exercise?” We did not reproduce the PPAQ response in categories, as commonly adopted; we used open responses to more accurately trace the frequency and duration of leisure-time walking in a typical week. Weekly walking time was calculated and evaluated according to the international recommendations: minimum of 150 minutes of moderate or vigorous physical activity per week for the pregnant woman to be considered active and consequently to be exposed to the benefits associated with this condition 15 .

The study was performed in accordance with the Declaration of Helsinki. The study was approved by the Ethics Research Committee of Botucatu Medical School, São Paulo State University (UNESP, orotocol n. 3989-2011S1). Informed written consent was obtained from all study participants for voluntary participation in Portuguese (national language). All data were coded and processed anonymously. All ongoing and related trials for this intervention are registered in the Clinical Trial Registry in Brazil (http://www.ensaiosclinicos.gov.br/; registration n. RBR-4mkg73).

\section{Outcome variables}

The dichotomous (yes or no) outcomes were as follows: (1) leisure-time walking; (2) achieves 150 minutes per week of leisure-time walking; (3) intake of at least one fruit 5 times per week or more; (4) intake of raw and baked vegetables 5 times per week or more; (5) intake of beans twice per day, 5 times per week or more; (6) intake of soft drinks and/or commercially prepared cookies no more than twice per week. Notably, the outcomes evaluated do not coincide with the recommendations for the intake of fruits ( 3 daily) and soft drinks and/or commercially prepared cookies (maximum of once per week) because in Botucatu, according to a previous study 24, only a small percentage of pregnant women followed these recommendations. Thus, we assessed whether there was an improvement in consumption rather than whether the recommendations were followed precisely.

\section{Data analysis}

The characteristics of the studied sample and losses to follow-up were compared using Student's t-test and chi-square test of homogeneity depending on the nature of the variable. The same tests were used to compare possible differences between the characteristics of the CG and IG.

The impact of the intervention was evaluated by a multilevel logistic regression analysis given the hierarchical organization of the data at three levels: $3^{\text {rd }}$ level = health units; $2^{\text {nd }}$ level = pregnant women; 1 st level = time/trimester. At the third level, the group variable characterized the presence or absence of the intervention; at the second level, the variables expressed the characteristics of the pregnant women; at the first level, the variable of time/trimester was a repetition of the information over time. 
For each of the six outcomes, the models introduced the intervention variables (or CG); time and the interaction term between the intervention and time. Given the initial differences between the groups, the measure used to determine the effect of the intervention in the second trimester was the interaction term between the intervention and time. The effect of the intervention during the third trimester was observed similarly to the ratio of the differences between the pre-pregnancy period and the third trimester between groups. In summary, the intervention effect was estimated as the ratio between the absolute differences in outcome between the time of interest and the pre-intervention time.

For variable selection, the "stepwise" method with "backward" elimination was used, retaining those associated with the outcome at $\mathrm{p} \leq 0.20$. Thus, the variables remaining in each final model had a statistical significance level of less than $5 \%$ and were those considered relevant based on the literature. The following variables were controlled for in models with leisure-time walking and achieving 150 minutes of leisure-time walking per week: maternal occupation, maternal education, cohabiting with a partner, environment, primigravida, pre-pregnancy BMI in $\mathrm{kg} / \mathrm{m}^{2}$, and pre-pregnancy alcohol intake. Analyses of diet were adjusted by maternal education, maternal occupation, maternal age, primigravida, pre-pregnancy BMI in $\mathrm{kg} / \mathrm{m}^{2}$ and pre-pregnancy alcohol intake. Statistical analyses were performed using Stata software version 13.1 (https://www.stata.com).

\section{Results}

During the recruitment period, 362 pregnant women (IG = 185 and CG = 177) were invited to participate in the study. Of these women, $3.2 \%$ of those in the IG and $4.3 \%$ of those in the CG refused to participate or could not be reached at home. There were losses in the second and third follow-ups, and 134 pregnant women in the IG and 133 in the CG participated in the data collection for all three trimesters of pregnancy. Figure 2 provides a flowchart of the study. No significant differences were observed between the participants surveyed $(n=267)$ and those lost to follow-up $(n=86)$, respectively, for maternal age (standar deviation $-\mathrm{SD}=25.9$, 5.6 years vs. $\mathrm{SD}=25.9 \mathrm{SD}, 6.5$ years; $\mathrm{p}=0.922$ ), years of education $(\mathrm{SD}=9.3,2.3$ years vs. $\mathrm{SD}=9.3 \mathrm{SD}, 2.9$ years; $\mathrm{p}=0.866$ ), nor regarding the outcomes investigated: leisure-time walking $(\mathrm{p}=0.708)$, achieves 150 minutes of leisure-time walking ( $\mathrm{p}=0.637)$, intake of fruit $(\mathrm{p}=0.650)$, vegetables $(\mathrm{p}=0.505)$, beans $(\mathrm{p}=0.356)$, soft drinks and/or commercially prepared cookies $(\mathrm{p}=0.119)$, data not shown in table.

The characteristics of the participants regarding socioeconomic, demographic, obstetric, behavioral and nutritional status are presented in Table 1. A greater percentage of pregnant women in the CG than IG had a paid job ( $\mathrm{p}=0.001)$, eight or more years of education $(\mathrm{p}=0.009)$, and were in class $\mathrm{B}$ in the socioeconomic classification ( $\mathrm{p}=0.011$ ). Regarding physical environment around the pregnant women's residences, more pregnant women in the IG (28.7\%) than in the CG (7\%) lived in an unfavorable environment $(\mathrm{p}<0.001)$.

Figure 3 presents changes in diet and physical activity of pregnant women between trimesters for both groups. There was a gradual increase in the proportion of pregnant women in the IG who engaged in leisure-time walking and a decrease followed by a small increase in the CG. During the pre-pregnancy period, the proportion of pregnant women who achieved the recommended 150 minutes per week of leisure-time walking was higher in the CG than in the GI $(\mathrm{p}=0.032)$. In the third trimester, the situation was reversed, with a higher proportion of pregnant women in the IG (11.9\%) than in the CG (9.8\%) achieving the recommendation; however, the difference in proportions in the third trimester was not significant $(\mathrm{p}=0.570)$. Concerning diet from the pre-pregnancy period to the third trimester, the percentage of pregnant women who consumed fruits and beans increased in both groups; the consumption of vegetables remained stable in the CG and fell in the IG; and there was a decrease in the proportion of pregnant women who consumed soft drinks and/or commercially prepared cookies. Comparisons between the groups in each trimester showed a significant difference for the consumption of soft drinks and/or commercially prepared cookies in the second trimester $(\mathrm{CG}=55.3 \%$ vs. $\mathrm{IG}=37.9 \%, \mathrm{p}=0.003)$ and third trimester $(\mathrm{CG}=51.1 \% \mathrm{vs} \mathrm{IG}=27.6 \%, \mathrm{p}<0.001)$.

Multilevel analysis showed a positive impact of the intervention on physical activity, even after adjusting for the covariates. The odds ratio of pregnant women in the IG engaging in leisure-time 


\section{Figure 2}

Flow chart of the study on the effectiveness of interventions designed to promote healthy diet and physical activity in antenatal care. Botucatu, São Paulo State, Brazil, 2012-2014.

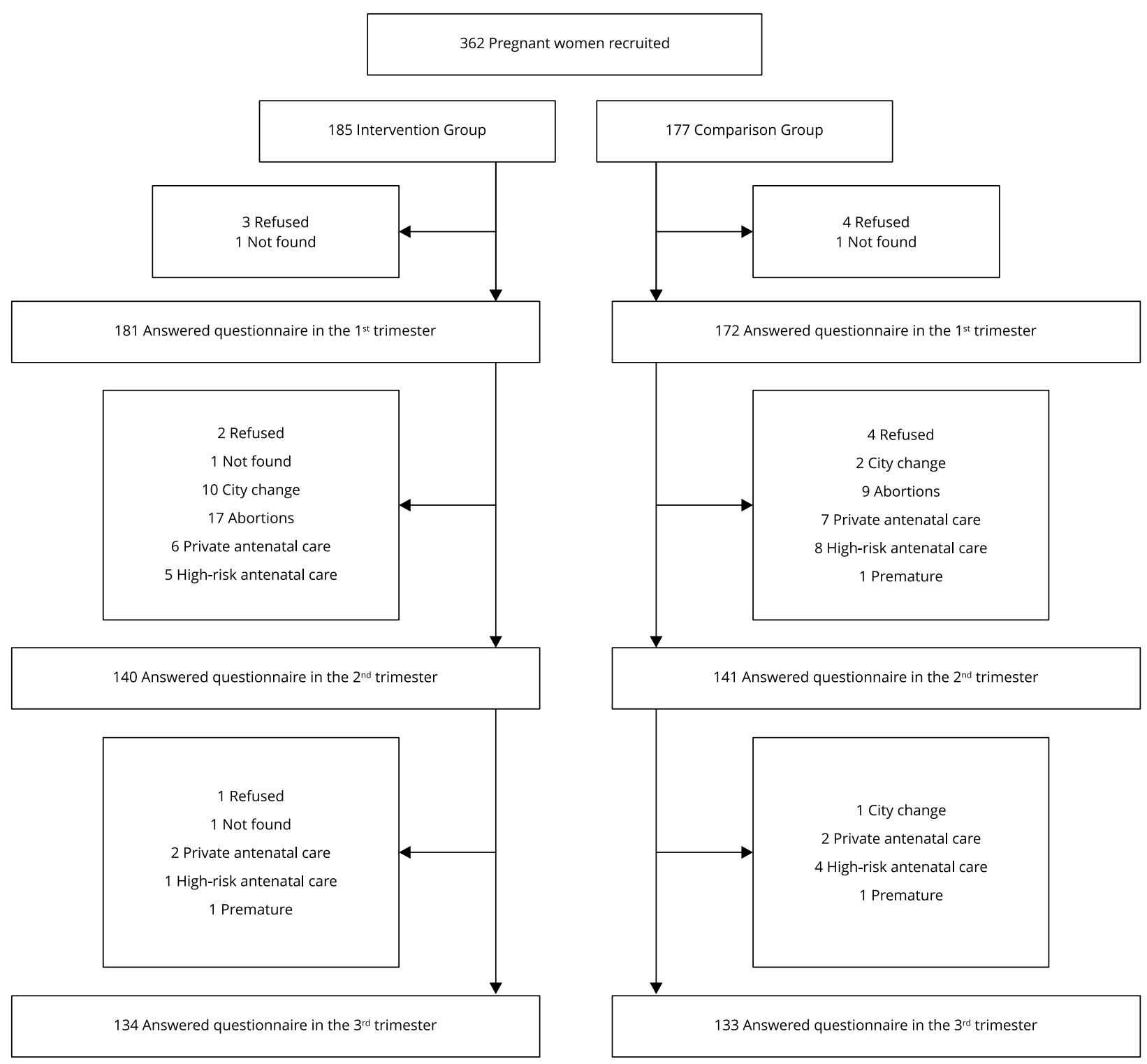

walking during the second trimester $(\mathrm{OR}=2.59,95 \% \mathrm{CI}$ : $1.04-6.42, \mathrm{p}=0.04)$ and third trimester $(\mathrm{OR}=3.33,95 \% \mathrm{CI}: 1.69-6.55, \mathrm{p}=0.001)$ of pregnancy were higher than those observed for the prepregnancy period and the CG. A similar effect was observed for the outcome of 150 minutes per week of leisure-time walking in the third trimester: $\mathrm{OR}=3.1,95 \% \mathrm{CI}: 1.24-7.75, \mathrm{p}=0.030$ (Table 2).

The intervention reduced the risk of pregnant women consuming soft drinks and/or commercially prepared cookies from the pre-pregnancy period to the third trimester. However, the intervention had no impact on the other dietary habits of pregnant women (Table 3). 
Table 1

Socioeconomic, demographic, obstetric, pre-pregnancy lifestyle and weight status characteristics of the pregnant women in the two groups. Botucatu, São Paulo State, Brazil, 2012-2014.

\begin{tabular}{|c|c|c|c|c|c|}
\hline \multirow[t]{2}{*}{ Characteristics } & \multicolumn{2}{|c|}{ Intervention $(n=181)$} & \multicolumn{2}{|c|}{ Comparison $(n=172)$} & \multirow[t]{2}{*}{ p-value * } \\
\hline & $\mathbf{n}$ & $\%$ & $\mathbf{n}$ & $\%$ & \\
\hline Maternal occupation, paid job & 69 & 38.1 & 101 & 58.7 & 0.000 \\
\hline Cohabiting with a partner, yes & 133 & 73.5 & 128 & 74.4 & 0.841 \\
\hline Maternal skin color, white & 112 & 62.9 & 113 & 65.7 & 0.588 \\
\hline \multicolumn{6}{|l|}{ Maternal age (years) } \\
\hline $18-19$ & 32 & 17.7 & 21 & 12.2 & \\
\hline $20 \mid-30$ & 107 & 59.1 & 103 & 59.9 & 0.282 \\
\hline $30 \mid$-more & 42 & 23.2 & 48 & 27.9 & \\
\hline \multicolumn{6}{|l|}{ Maternal education (years) } \\
\hline$\geq 8$ & 130 & 71.2 & 146 & 84.9 & 0.003 \\
\hline$<8$ & 51 & 28.2 & 26 & 15.1 & \\
\hline \multicolumn{6}{|l|}{ Socioeconomic position ** } \\
\hline Class B & 14 & 8.0 & 20 & 11.8 & \\
\hline Class C & 112 & 63.6 & 123 & 72.8 & $0.011 * * *$ \\
\hline Classes D/E & 50 & 28.4 & 26 & 15.4 & \\
\hline Physical environment, unfavorable \# & 51 & 28.7 & 12 & 7.0 & 0.000 \\
\hline Primigravida & 71 & 39.2 & 78 & 45.3 & 0.244 \\
\hline Pre-pregnancy weight status \#\# & & & & & 0.263 \\
\hline Underweight & 08 & 4.7 & 09 & 5.4 & \\
\hline Normal weight & 91 & 53.2 & 71 & 42.5 & \\
\hline Overweight & 43 & 25.1 & 54 & 32.3 & \\
\hline Obesity & 29 & 17.0 & 33 & 19.8 & \\
\hline Pre-pregnancy tobacco use, yes & 46 & 25.4 & 44 & 26.6 & 0.971 \\
\hline \multirow[t]{2}{*}{ Pre-pregnancy alcohol intake, yes } & 67 & 37.0 & 69 & 40.1 & 0.550 \\
\hline & Mean & SD & Mean & SD & p-value \#\#\# \\
\hline Maternal age (years) & 25.4 & 6.1 & 26.3 & 5.7 & 0.140 \\
\hline Gestational age 1st trimester (weeks) & 8.6 & 2.7 & 8.6 & 2.2 & 1.000 \\
\hline Gestational age $2^{\text {nd }}$ trimester (weeks) & 25.6 & 1.3 & 25.3 & 1.7 & 0.222 \\
\hline Gestational age 3rd trimester (weeks) & 32.7 & 1.4 & 32.6 & 1.2 & 0.693 \\
\hline Pre-pregnancy BMI (kg/m²) & 25.3 & 5.7 & 26.0 & 5.6 & 0.910 \\
\hline
\end{tabular}

BMI: body mass index; SD: standard deviation.

Note: totals differ due to missing values.

* Chi-square test of homogeneity;

** Classified according to the Brazilian Association of Research Companies (ABEP. http://www.abep.org/, accessed on 10/ May/2015):

*** Fisher's exact test;

\# Favorable environment refers to the presence of asphalt, paving and street lighting, while unfavorable environment refers to the absence of one of these factors;

\#\# Classified according to the references proposed by the World Health Organization 50 for adults; \#\#\# Student's t-test. 
Figure 3

Changes in physical activity and diet of pregnant women between trimesters for both groups. Botucatu, São Paulo State, Brazil, $2012-2014$.

3a) Leisure-time walking
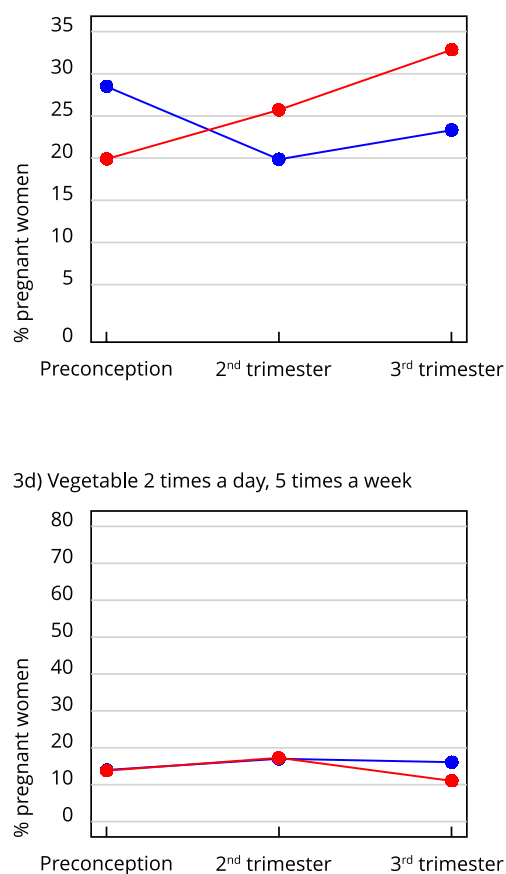
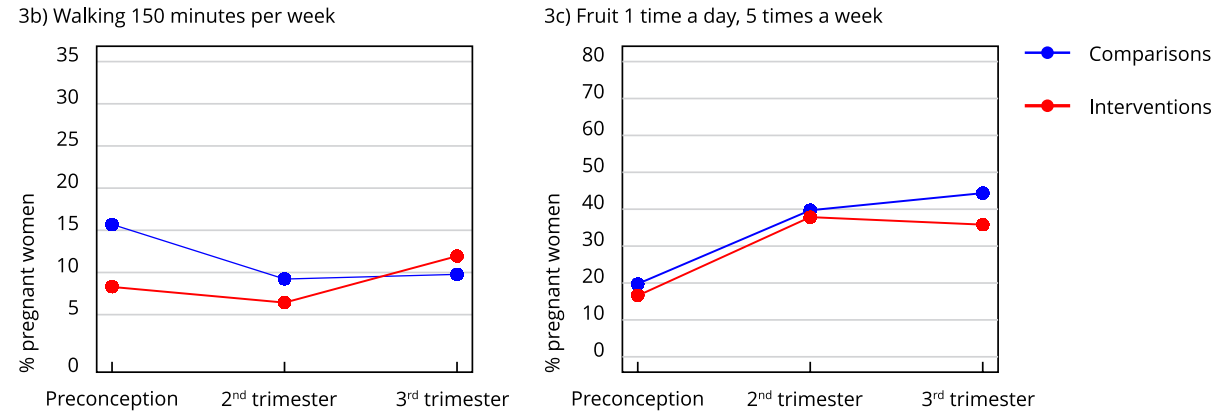

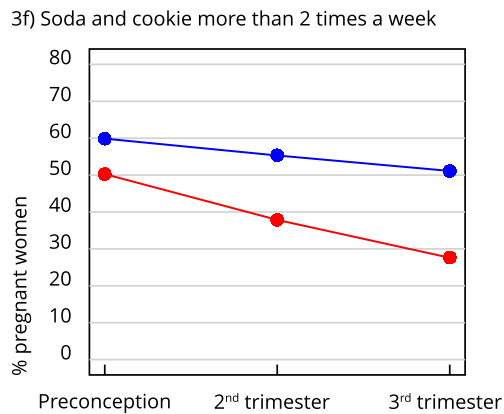

Note: chi-square test of homogeneity.

Figure 4 highlights the magnitude of the effects of the intervention, which was largest in the third trimester, during which time the intervention tripled the odds of pregnant women engaging in leisure-time walking and achieving 150 minutes of walking per week and reduced the odds of high consumption of soft drinks and/or commercially prepared cookies.

\section{Discussion}

One of the most important results of the present study was the positive effect of the promotion of walking in a population (pregnant women) that traditionally does not perform physical activity: the intervention was able to increase the percentage of pregnant women who walked regularly and achieved 150 minutes per week of walking in leisure time. The literature has shown that the physical activity levels of pregnant women are often lower than those of the general population 32 and that the levels of physical activity decrease with advanced gestation 33, indicating the enormous challenge to health services and the need to promote and facilitate physical activity among pregnant women. Our pragmatic intervention supports the potential of physical activity promotion to become a routine activity in the primary health care network in Brazil.

When we compared the percentage of CG pregnant women who engaged in physical activity for more than 150 minutes per week (9.8\%) in the third trimester, the percentage was very close to that obtained among American pregnant women in an observational study (9.3\%) 34. Despite the great cultural and socioeconomic differences between Brazilian and American pregnant women, the low percentage of those that perform physical activity according to the recommendation is a common 
Table 2

Impact of the intervention in diet and physical activity on the practice of leisure-time walking and achieving 150 minutes per week of walking by pregnant women. Botucatu, São Paulo State, Brazil, 2012-2014.

\begin{tabular}{|c|c|c|c|c|c|c|}
\hline & \multicolumn{3}{|c|}{ Crude } & \multicolumn{3}{|c|}{ Adjusted * } \\
\hline & OR & $95 \% \mathrm{Cl}$ & p-value & OR & $95 \% \mathrm{Cl}$ & p-value \\
\hline \multicolumn{7}{|c|}{ Leisure-time walking } \\
\hline \multicolumn{7}{|l|}{ Group } \\
\hline Comparison & 1.00 & & & 1.00 & & \\
\hline Intervention & 0.55 & $0.28-1.08$ & 0.084 & 0.57 & $0.22-1.48$ & 0.245 \\
\hline \multicolumn{7}{|l|}{ Time } \\
\hline Pre-pregnancy & 1.00 & & & 1.00 & & \\
\hline 2 nd trimester ** & 0.56 & $0.32-0.99$ & 0.044 & 0.54 & $0.26-1.12$ & 0.098 \\
\hline 3rd trimester $* * *$ & 0.74 & $0.86-1.77$ & 0.037 & 0.46 & $0.48-0.86$ & 0.003 \\
\hline \multicolumn{7}{|c|}{ Interaction group time (trimester) } \\
\hline Intervention $2^{\text {nd }}$ & 2.63 & $1.13-6.15$ & 0.025 & 2.59 & $1.04-6.42$ & 0.040 \\
\hline Intervention 3rd & 3.15 & $1.69-5.84$ & 0.000 & 3.33 & $1.69-6.55$ & 0.001 \\
\hline \multicolumn{7}{|c|}{ Achieves 150 minutes/week of walking } \\
\hline \multicolumn{7}{|l|}{ Group } \\
\hline Comparison & 1.00 & & & 1.00 & & \\
\hline Intervention & 0.41 & $0.18-0.96$ & 0.039 & 0.54 & $0.19-1.59$ & 0.266 \\
\hline \multicolumn{7}{|l|}{ Time } \\
\hline Pre-pregnancy & 1.00 & & & 1.00 & & \\
\hline $2^{\text {nd }}$ trimester $* *$ & 0.48 & $0.17-1.40$ & 0.178 & 0.43 & $0.16-1.18$ & 0.101 \\
\hline 3 rd trimester $* * *$ & 0.52 & $0.26-1.05$ & 0.069 & 0.47 & $0.24-0.93$ & 0.030 \\
\hline \multicolumn{7}{|c|}{ Interaction group time (trimester) } \\
\hline Intervention 2nd & 1.43 & $0.35-5.92$ & 0.620 & 1.61 & $0.40-6.54$ & 0.503 \\
\hline Intervention 3rd & 2.99 & $1.24-7.23$ & 0.015 & 3.10 & $1.24-7.75$ & 0.016 \\
\hline
\end{tabular}

95\%Cl: 95\% confidence interval; OR: odds ratio.

Note: multilevel logistic regression test.

* Adjusted for maternal occupation, maternal education, cohabiting with a partner, environment, primigravida, prepregnancy body mass index in $\mathrm{kg} / \mathrm{m}^{2}$, and pre-pregnancy alcohol intake;

** Intervention group $n=140$, comparison group $n=141$;

$* \star *$ Intervention group $\mathrm{n}=134$, comparison group $\mathrm{n}=133$.

characteristic among them. Moreover, in the United States there is evidence of the positive effect of the advice of health professionals on the practice of physical activity by pregnant women 34 .

Even considering the positive result of the intervention outlined and evaluated by us, it is worth highlighting that in the IG the percentage of pregnant women who walked the recommended amount (150 minutes or more per week) was still very unsatisfactory, indicating that there is a limit in its potential to produce changes in the behavior of pregnant women. Although the encouragement and support of antenatal care providers encouraged a portion of pregnant women to become more active, it was insufficient for most pregnant women to become active.

In pregnant women in particular, little is known regarding the determinants of physical activity. In adults in general, it is known that there are multiple associated factors, which act at different levels, according to the theoretical model used in our study (Figure 1). The intervention administered in our study covers only individual and few interpersonal determinants related to the promotion and guidance of physical activity and diet by professionals in primary health care units. This design was chosen because several studies have found that, among the several factors that can influence dietary behavioral changes and physical activity, the guidance and support provided by health professionals is the most influential 22,35. However, the results of the studies show that this type of intervention 
Table 3

Impact of the intervention in diet and physical activity on the high consumption of soft drinks and/or commercially prepared cookies and low consumption of fruits, vegetables and beans by pregnant women. Botucatu, São Paulo State, Brazil, 2012-2014.

\begin{tabular}{|c|c|c|c|c|c|c|}
\hline & \multicolumn{3}{|c|}{ Crude } & \multicolumn{3}{|c|}{ Adjusted * } \\
\hline & OR & $95 \% \mathrm{Cl}$ & p-value & OR & $95 \% \mathrm{Cl}$ & p-value \\
\hline \multicolumn{7}{|c|}{ Soft drinks/cookies more than 2 times per week } \\
\hline \multicolumn{7}{|l|}{ Group } \\
\hline Comparison & 1.00 & & & 1.00 & & \\
\hline Intervention & 0.58 & $0.36-0.92$ & 0.021 & 0.50 & $0.29-0.85$ & 0.011 \\
\hline \multicolumn{7}{|l|}{ Time } \\
\hline Pre-pregnancy & 1.00 & & & 1.00 & & \\
\hline $2^{\text {nd }}$ trimester ** & 0.75 & $0.45-1.23$ & 0.249 & 0.75 & $0.52-1.06$ & 0.104 \\
\hline 3rd trimester $* * *$ & 0.58 & $0.46-0.73$ & 0.000 & 0.59 & $0.46-0.77$ & 0.000 \\
\hline \multicolumn{7}{|c|}{ Interaction group time (trimester) } \\
\hline Intervention 2nd & 0.66 & $0.30-1.44$ & 0.300 & 0.75 & $0.35-1.59$ & 0.451 \\
\hline Intervention 3rd & 0.46 & $0.25-0.85$ & 0.013 & 0.49 & $0.24-0.98$ & 0.045 \\
\hline \multicolumn{7}{|c|}{ Fruits (at least 1) 5 times per week } \\
\hline \multicolumn{7}{|l|}{ Group } \\
\hline Comparison & 1.00 & & & 1.00 & & \\
\hline Intervention & 0.74 & $0.312-1.76$ & 0.498 & 0.96 & $0.37-2.52$ & 0.934 \\
\hline \multicolumn{7}{|l|}{ Time } \\
\hline Pre-pregnancy & 1.00 & & & 1.00 & & \\
\hline $2^{\text {nd }}$ trimester $* *$ & 4.65 & $3.06-7.06$ & 0.000 & 4.74 & $2.94-7.62$ & 0.000 \\
\hline 3rd trimester $* * *$ & 6.20 & 3.87-9.94 & 0.000 & 7.44 & $4.49-12.34$ & 0.000 \\
\hline \multicolumn{7}{|c|}{ Interaction group time (trimester) } \\
\hline Intervention 2nd & 1.33 & $0.45-3.91$ & 0.603 & 1.19 & $0.34-4.14$ & 0.786 \\
\hline Intervention 3rd & 0.87 & $0.28-2.70$ & 0.804 & 0.56 & $0.16-2.05$ & 0.384 \\
\hline \multicolumn{7}{|c|}{ Vegetables ( 1 raw and 1 cooked) 5 times per week } \\
\hline \multicolumn{7}{|l|}{ Group } \\
\hline Comparison & 1.00 & & & 1.00 & & \\
\hline Intervention & 0.98 & $0.52-1.85$ & 0.949 & 0.92 & $0.47-1.80$ & 0.810 \\
\hline \multicolumn{7}{|l|}{ Time } \\
\hline Pre-pregnancy & 1.00 & & & 1.00 & & \\
\hline $2^{\text {nd }}$ trimester $* *$ & 1.20 & $0.69-2.07$ & 0.525 & 0.97 & $0.54-1.73$ & 0.905 \\
\hline 3rd trimester $* \star \star$ & 0.55 & $0.38-0.78$ & 0.001 & 0.96 & $0.45-2.02$ & 0.905 \\
\hline \multicolumn{7}{|c|}{ Interaction group time (trimester) } \\
\hline Intervention 2nd & 0.87 & $0.31-2.39$ & 0.780 & 1.25 & $0.56-2.76$ & 0.586 \\
\hline Intervention 3rd & 1.54 & $0.60-3.91$ & 0.368 & 0.73 & $0.26-2.07$ & 0.549 \\
\hline \multicolumn{7}{|c|}{ Beans (lunch and dinner) 5 times per week } \\
\hline \multicolumn{7}{|l|}{ Group } \\
\hline Comparison & 1.00 & & & 1.00 & & \\
\hline Intervention & 2.99 & $1.48-6.01$ & 0.002 & 1.77 & $1.00-3.15$ & 0.050 \\
\hline \multicolumn{7}{|l|}{ Time } \\
\hline Pre-pregnancy & 1.00 & & & 1.00 & & \\
\hline $2^{\text {nd }}$ trimester $* *$ & 2.09 & $1.37-3.17$ & 0.001 & 2.18 & $1.39-3.42$ & 0.001 \\
\hline 3rd trimester $* * *$ & 2.37 & $1.00-5.65$ & 0.051 & 2.62 & $1.04-6.57$ & 0.041 \\
\hline \multicolumn{7}{|c|}{ Interaction group time (trimester) } \\
\hline Intervention 2nd & 0.79 & $0.39-1.61$ & 0.521 & 0.61 & $0.24-1.53$ & 0.293 \\
\hline Intervention 3rd & 0.97 & $0.38-2.49$ & 0.947 & 0.81 & $0.27-2.49$ & 0.717 \\
\hline
\end{tabular}

95\% Cl: 95\% confidence interval; OR: odds ratio.

Note: multilevel logistic regression test.

* Adjusted for maternal occupation, maternal education, cohabiting with a partner, environment, primigravida,

pre-pregnancy body mass index in $\mathrm{kg} / \mathrm{m}^{2}$, and pre-pregnancy alcohol intake;

** Intervention group $n=140$, comparison group $n=141$;

$\star * *$ Intervention group $\mathrm{n}=134$, comparison group $\mathrm{n}=133$. 


\section{Figure 4}

Magnitude of the positive effects of the intervention in physical activity and diet on the second and third trimesters of pregnancy. Botucatu, São Paulo State, Brazil, 2012-2014.

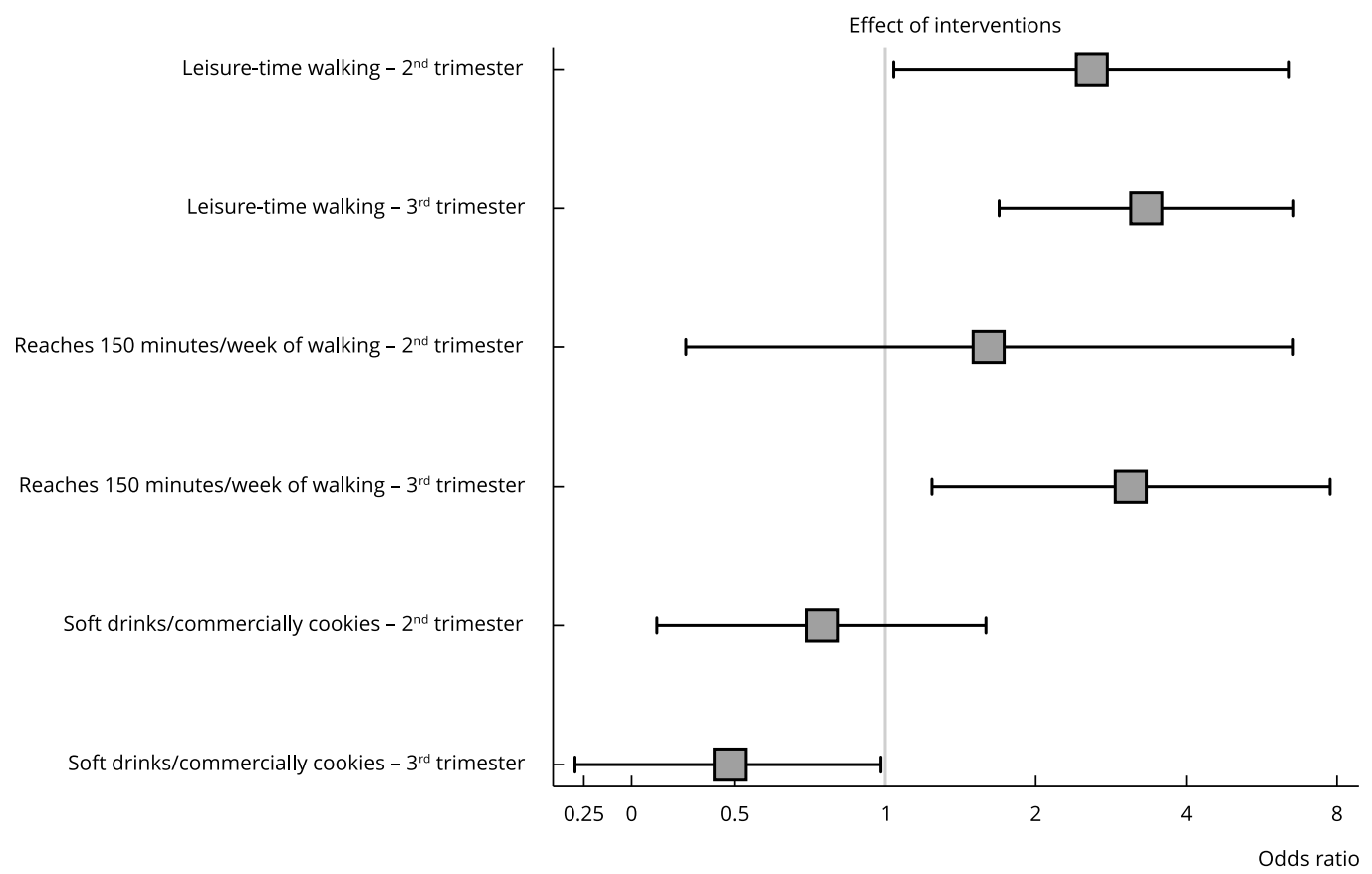

should be complemented with actions on other determinants, such as the physical environment, and engage other participants of the pregnant woman's social support network, such as family members and neighbors, which could have led to higher-impact outcomes. One example is the stimulation of walking groups, an action that the literature indicates as effective for positive health outcomes in the general population ${ }^{36}$. In addition, this intervention is compatible with the Brazilian model of primary health care: universal, public and of free access.

Barriers to pregnant women performing physica activity have been the subject of few investigations 37 . In the international literature, a small study carried out in Portugal and another one, with a large sample of US pregnant women, found common barriers, such as the lack of time due to work, tiredness, or simply the fact that they do not like to exercise 38,39,40. Such barriers are intrapersonal, but for them to be overcome, in addition to encouragement during antenatal visits, it is important to show the importance of physical activity throughout pregnancy and to instruct on how to perform it safely. Changes in the environment also are necessary 41 . These barriers imply new perspectives for urban planning, work environments, the division of domestic work and childcare, among other spheres of human life that need to become more conducive to the performance of physical activity by all, including pregnant women.

Regarding the diet of pregnant women, the impact of the intervention was lower than expected. In the literature, there are successful 13 and unsuccessful 42 interventions that attempt to increase the consumption of vegetables and fruits by pregnant women. It is possible that the actions aimed at promoting a healthy diet were not implemented with sufficient intensity to induce lifestyle changes. A study evaluated two different interventions: (i) a folder with dietary information and physical activity recommendations provided during the first antenatal visit; and (ii) a folder and three counseling group sessions conducted by a team of nutritionists. The study showed a positive impact of both 
interventions on the consumption of vegetables but not on the consumption of fruits 43 . The intervention designed by Dodd et al. 13, which increased pregnant women's consumption of fruits and vegetables, included more actions: a planning session with a nutritionist who developed an individualized eating plan and provided a food diary, a cookbook and examples of healthy menus, in addition to six additional meetings with the nutritionist to reinforce the intervention (two in-person and four via phone). Among pregnant women from Istanbul, delivery of individualized material and periodic meetings with the research team also increased vegetable consumption 44. It is important to note that these models differ from the intervention evaluated here, as the interest was a feasible model that can be routinely conducted in antenatal care.

In a study conducted in Germany, with an intervention similar to ours, there was a reduction in the consumption of sodas and an increase in the consumption of vegetables, with no change in energy consumption, which was pointed by the authors as a possible explanation for the lack of effect on the risk of excessive gestational weight gain ${ }^{14}$. There is a study in the literature suggesting that the reduction in discretionary foods may not have an effect on overall caloric reduction, as it may induce increased consumption of other foods; thus, change in one unhealthy eating behavior does not guarantee change in diet as a whole 45 . One hypothesis to explain our result could be that removing discretionary foods is easier than adding healthier foods. This may explain a favorable result in reducing the consumption of soft drinks and commercially prepared cookies but not in improving the consumption of fruits, vegetables and beans. The success of interventions aimed at promoting healthy behaviors depends on an understanding of the factors that determine these behaviors, as presented in our theoretical framework. Among the factors that influenced the consumption of fruits and vegetables found by a qualitative study on pregnant women of Latin origin living in the United States, the social support of family and friends was determined as the most important; access to such products, family structure, preferences, and knowledge of the benefits also have influence 46 .

It is important to highlight that the factors related to changes in diet and physical activity behaviors may not be the same and may differ during pregnancy. In a qualitative study investigating these habits among nurses, work routine, being hungry, decreased self-control, food choices, and overeating were the factors that most influenced their eating habits. In contrast, regarding physical activity habits, fatigue and lack of time were the factors that most influenced their behaviors 47 . Among pregnant women, the motivation for changes in diet seems to be more about considering the outcomes of gestation and not their own health. Regarding physical activity, the sociocultural context is fundamental; older pregnant women show a greater understanding of the importance of physical activity, and the self-efficacy to exercise is very important in this population 48 .

As is widely known, it is essential to evaluate process indicators to understand the impact of an intervention. In a previous article, these indicators were assessed and indicated that the intervention was conducted in most antenatal visits. In interviews at home, in the second and third trimesters of pregnancy, $50.7 \%$ and $58.6 \%$ of the pregnant women, respectively, reported that they had received counseling on walking and adopting a healthy diet in the previous antenatal visits 19 . Although the professionals were encouraged to promote these healthy behaviors at all antenatal visits, it is understandable that providing such guidance was not always possible due to the emergence of other priority situations, such as complications during pregnancy.

Some aspects of the internal validity of this study warrant discussion. Prospective studies should assess the magnitude and the possible effect of loss to follow-up. Because there were no differences in the socioeconomic characteristics, obstetric data and behavior of pregnant women who were no longer followed and of those who remained in the study and because the magnitude and reasons for losses to follow-up were similar in the two groups, the study did not seem to suffer from selection bias due to loss to follow-up. However, with the losses, the sample followed up to the third gestational trimester did not reach the minimum size estimated as necessary to detect the expected differences in dietary practices, which is a limitation to be considered.

Another limitation of this study is the use of a non-objective method for assessing the practice of physical activity. However, it should be noted that physical activity measurement is a challenging area for health promotion. Self-reported measures have relatively low cost, high acceptability, and are convenient for evaluation of physical activity during leisure time on the adult population 49. Although physical activity is a complex behavior to measure, the present intervention was focused on a single 
target, walking during leisure time, and not on all domains of physical activity. Another limitation of this study is the fact that there was no previous validation of the Vigitel food questionnaire for application to pregnant women.

Finally, in extrapolating results, caution is important. Our study included only low-risk obstetric pregnant women served at public antenatal health care services. Thus, little information is available on pregnant women at higher risk for complications during pregnancy, or on higher-income women, who commonly do not use the Brazilian public health care service.

Considering the limited results, in new studies, in addition to the actions conducted by physicians and nurses in routine antenatal visits, health agents or community leaders could expand the intervention with actions also focused on the contextual determinants of physical activity and diet of pregnant women. This new model of intervention would still be compatible with the Brazilian public health care system 18 . Examples of new actions to be introduced and evaluated in future studies: physical activity sessions with community health workers who could lead walking groups with pregnant women and conduct culinary workshops, in addition to mapping food markets for purchasing cheaper fruits and vegetables. Additionally, new interventions could assess whether pregnant women at different stages of behavioral change would lead to different results.

Another hypothesis to be evaluated by future studies is the impact of incorporating specialists to work in conjunction with generalist professionals. The introduction of nutritionists and movement professionals (including physical therapists, exercise physiologists or physical educators) in Brazilian primary health care units and their participation in antenatal care to specifically promote physical activity and healthy diet among pregnant women also deserves to be tested in future studies, even if, currently, this do not seem to be the most viable option for Brazil.

Although the intervention should be scaled up and tailored, it was partially effective and its results already support that health professionals in antenatal routine can positively impact the physical activity and some dietary behavior of pregnant women. 


\section{Contributors}

M. B. Malta contributed in the study conception, design and analysis and interpretation of data, writing the article. C. B. Gomes contributed in the data analysis and interpretation, writing the article. A. J. D. Barros and L. G. Baraldi contributed in the analysis and interpretation of data and relevant critical review of intellectual content. M. Y. Takito contributed in the conception and project, writing of the article, and relevant critical review of the intellectual content. M. H. D’A. Benício and M. A. B. L. Carvalhaes contributed in the conception, study design, analysis, interpretation of data, and relevant critical review of intellectual content. All authors contributed to the final approval of the version to be published, and are responsible for all aspects of the work in ensuring the accuracy and integrity of any part of the work.

\section{Additional informations}

ORCID: Maíra Barreto Malta (0000-0003-49931589); Caroline de Barros Gomes (0000-00029576-4251); Aluísio J. D. Barros (0000-0002-20228729); Larissa Gastraldi Baraldi (0000-0002-67937899); Monica Yuri Takito (0000-0003-0257-8765); Maria Helena D’Aquino Benício (0000-0003-18511178); Maria Antonieta de Barros Leite Carvalhaes (0000-0002-6695-0792).

\section{Acknowledgments}

We acknowledge the staff at the Research Unit on Collective Health, Botucatu Medical School, São Paulo State University, the interviewers, the professionals from the Botucatu, São Paulo State primary health care network, and the pregnant women who made this study possible.

\section{References}

1. Barakat R, Refoyo I, Coteron J, Franco E. Exercise during pregnancy has a preventative effect on excessive maternal weight gain and gestational diabetes. A randomized controlled trial. Braz J Phys Ther 2019; 23:148-55.

2. Silva SG, Ricardo LI, Evenson KR, Hallal PC. Leisure-time physical activity in pregnancy and maternal-child health: a systematic review and meta-analysis of randomized controlled trials and cohort studies. Sport Med 2017; 47:295-317.

3. Emond JA, Karagas MR, Baker ER, Gilbert-Diamond D. Better diet quality during pregnancy is associated with a reduced likelihood of an infant born small for gestational age: an analysis of the prospective New Hampshire Birth Cohort Study. J Nutr 2018; 148:22-30.

4. Lindsay KL, Heneghan C, McNulty B, Brennan L, McAuliffe FM. Lifestyle and dietary habits of an obese pregnant cohort. Matern Child Health J 2015; 19:25-32.

5. Ekelin M, Langeland Iversen M, Grønbæk Backhausen M, Hegaard HK. Not now but later - a qualitative study of non-exercising pregnant women's views and experiences of exercise. BMC Pregnancy Childbirth 2018; 18: 399.

6. Carvalhaes MABL, Martiniano ACA, Malta MB, Takito MY, Benício MHD. Physical activity in pregnant women receiving care in primary health care units. Rev Saúde Pública 2013; 47:958-67.

7. Teixeira JA, Castro TG, Grant CC, Wall CR, Castro ALS, Francisco RPV, et al. Dietary patterns are influenced by socio-demographic conditions of women in childbearing age: a cohort study of pregnant women. BMC Public Health 2018; 18:301.

8. Baião MR, Deslandes SF. Práticas alimentares na gravidez: um estudo com gestantes e puérperas de um complexo de favelas do Rio de Janeiro (RJ, Brasil). Ciênc Saúde Colet 2010; 15:3199-206.

9. Jen V, Erler NS, Tielemans MJ, Braun KV, Jaddoe VW, Franco OH, et al. Mothers' intake of sugar-containing beverages during pregnancy and body composition of their children during childhood: the Generation R Study. Am J Clin Nutr 2017; 105:834-41.

10. Thangaratinam S, Rogozinska E, Jolly K, Glinkowski S, Roseboom T, Tomlinson JW, et al. Effects of interventions in pregnancy on maternal weight and obstetric outcomes: meta-analysis of randomised evidence. BMJ 2012; 344:e2088.

11. Jing W, Huang Y, Liu X, Luo B, Yang Y, Liao S. The effect of a personalized intervention on weight gain and physical activity among pregnant women in China. Int J Gynecol Obstet 2015; 129:138-41. 
12. Poston L, Bell R, Croker H, Flynn AC, Godfrey KM, Goff L, et al. Effect of a behavioural intervention in obese pregnant women (the UPBEAT study): a multicentre, randomised controlled trial. Lancet Diabetes Endocrinol 2015; 3:P767-77.

13. Dodd JM, Cramp C, Sui Z, Yelland LN, Deussen AR, Grivell RM, et al. The effects of antenatal dietary and lifestyle advice for women who are overweight or obese on maternal diet and physical activity: the LIMIT randomised trial. BMC Med 2014; 12:161.

14. Günther J, Hoffmann J, Kunath J, Spies M, Meyer D, Stecher L, et al. Effects of a lifestyle intervention in routine care on prenatal dietary behavior - findings from the cluster-randomized GeliS Trial. J Clin Med 2019; 8:960.

15. American College of Gynecologists Obstetricians. Physical activity and exercise during pregnancy and the postpartum period. Obstet Gynecol 2020; 135:991-3.

16. Coordenação Geral de Alimentação e Nutrição, Ministério da Saúde. Alimentação saudável para gestantes: siga os dez passos. http:// 189.28.128.100/nutricao/docs/geral/10pas sosGestantes.pdf (accessed on 27/Nov/2018).

17. Instituto Brasileiro de Geografia e Estatística. Pesquisa Nacional por Amostra de Domicílios. http://www.ibge.gov.br/home/estatistica/ pesquisas/pesquisa_resultados.php?id_pesqui sa $=40$ (accessed 27/Nov/2018).

18. Paim J, Travassos C, Almeida C, Bahia L, Macinko J. The Brazilian health system: history, advances, and challenges. Lancet 2011; 377:1778-97.

19. Malta MB, Carvalhaes MABL, Takito MY, Tonete VLP, Barros AJD, Parada CMGL, et al. Educational intervention regarding diet and physical activity for pregnant women: changes in knowledge and practices among health professionals. BMC Pregnancy Childbirth 2016; 16:175.

20. Departamento de Atenção Básica, Secretaria de Atenção à Saúde, Ministério da Saúde. Atenção ao pré-natal de baixo risco. Brasília: Ministério da Saúde; 2012.

21. Meltzer HM, Brantsæter AL, Nilsen RM, Magnus P, Alexander J, Haugen M. Effect of dietary factors in pregnancy on risk of pregnancy complications: results from the Norwegian Mother and Child Cohort Study. Am J Clin Nutr 2011; 94(6 Suppl):1970S-4S.

22. Prochaska JO, Velicer WF. The transtheoretical model of health behavior change. Am J Health Promot 1997; 12:38-48.

23. Miller W, Rollnick S. Motivational interviewing - preparing people for change. 2nd Ed. New York: Guilford Press; 2002.

24. Gomes CB, Malta MB, Martiniano ACA, Di Bonifácio LP, Carvalhaes MABL. Eating habits of pregnant and non-pregnant women: are there differences? Rev Bras Ginecol Obstet $2015 ; 37: 325-32$.
25. Palombarini AF, Malta MB, Parada CMGL, Carvalhaes MABL, Benício MHD, Tonete VLP. Nutritional practices of expectant mothers supported by a Family Health Unit: an exploratory study. Online Brazil J Nurs 2014; 13:186-97.

26. Departamento de Atenção Básica, Secretaria de Atenção à Saúde, Ministério da Saúde. Guia alimentar para a população brasileira. Brasília: Ministério da Saúde; 2015.

27. Physical Activity Guidelines Advisory Committee report, 2008. To the Secretary of Health and Human Services. Part A: executive summary. Nutr Rev 2009; 67:114-20.

28. Bauman AE, Reis RS, Sallis JF, Wells JC, Loos RJF, Martin BW. Correlates of physical activity: why are some people physically active and others not? Lancet 2012; 380:258-71.

29. Giles-Corti B. People or places: what should be the target? J Sci Med Sport 2006; 9:357-66.

30. Souza ADM, Bezerra IN, Cunha DB, Sichieri R. Evaluation of food intake markers in the Brazilian surveillance system for chronic diseases - VIGITEL (2007-2009). Rev Bras Epidemiol 2011; 14 Suppl 1:44-52.

31. Chasan-Taber L, Schmidt MD, Roberts DE, Hosmer D, Markenson G, Freedson PS. Development and validation of a Pregnancy Physical Activity Questionnaire. Med Sci Sport Exerc 2004; 36:1750-60.

32. Hausenblas H, Giacobbi P, Cook B, Rhodes R, Cruz A. Prospective examination of pregnant and nonpregnant women's physical activity beliefs and behaviours. J Reprod Infant Psychol 2011;29:308-19.

33. Coll CDVN, Domingues MR, Hallal PC, Silva ICM, Bassani DG, Matijasevich A, et al. Changes in leisure-time physical activity among Brazilian pregnant women: comparison between two birth cohort studies (20042015). BMC Public Health 2017; 17:119.

34. Santo EC, Forbes PW, Oken E, Belfort MB. Determinants of physical activity frequency and provider advice during pregnancy. BMC Pregnancy Childbirth 2017; 17:286.

35. de Jersey SJ, Nicholson JM, Callaway LK, Daniels LA. An observational study of nutrition and physical activity behaviours, knowledge, and advice in pregnancy. BMC Pregnancy Childbirth 2013; 13:115.

36. Hanson S, Jones A. Is there evidence that walking groups have health benefits? A systematic review and meta-analysis. Br J Sports Med 2015; 49:710-5.

37. Harrison AL, Taylor NF, Shields N, Frawley HC. Attitudes, barriers and enablers to physical activity in pregnant women: a systematic review. J Physiother 2018; 64:24-32.

38. Santos PC, Abreu S, Moreira C, Lopes D, Santos R, Alves O, et al. Impact of compliance with different guidelines on physical activity during pregnancy and perceived barriers to leisure physical activity. J Sports Sci 2014; 32:1398408. 
39. Evenson KR, Moos M-K, Carrier K, Siega-Riz AM. Perceived barriers to physical activity among pregnant women. Matern Child Health J 2009; 13:364-75.

40. Evenson KR, Bradley CB. Beliefs about exercise and physical activity among pregnant women. Patient Educ Couns 2010; 79:124-9.

41. da Silva ICM, Hino AA, Lopes A, Ekelund U, Brage S, Gonçalves $\mathrm{H}$, et al. Built environment and physical activity: domain- and activityspecific associations among Brazilian adolescents. BMC Public Health 2017; 17:616.

42. Kunath J, Günther J, Rauh K, Hoffmann J, Stecher L, Rosenfeld E, et al. Effects of a lifestyle intervention during pregnancy to prevent excessive gestational weight gain in routine care - the cluster-randomised GeliS trial. BMC Med 2019; 17:5.

43. Guelinckx I, Devlieger R, Mullie P, Vansant G. Effect of lifestyle intervention on dietary habits, physical activity, and gestational weight gain in obese pregnant women: a randomized controlled trial. Am J Clin Nutr 2010; 91:37380.

44. Aşc1 Ö, Rathfisch G. Effect of lifestyle interventions of pregnant women on their dietary habits, lifestyle behaviors, and weight gain: a randomized controlled trial. J Health Popul Nutr 2016; 35:7.

45. Grieger JA, Johnson BJ, Wycherley TP, Golley RK. Evaluation of simulation models that estimate the effect of dietary strategies on nutritional intake: a systematic review. J Nutr 2017; 147:908-31.
46. Hromi-Fiedler A, Chapman D, Segura-Pérez S, Damio G, Clark P, Martinez J, et al. Barriers and facilitators to improve fruit and vegetable intake among WIC-Eligible Pregnant Latinas: an application of the health action process approach framework. J Nutr Educ Behav 2016; 48:468-77.e1.

47. Torquati L, Kolbe-Alexander T, Pavey T, Persson C, Leveritt M. Diet and physical activity behaviour in nurses: a qualitative study. Int J Heal Promot Educ 2016; 54:268-82.

48. O’Brien OA, Lindsay KL, McCarthy M, McGloin AF, Kennelly M, Scully HA, et al. Influences on the food choices and physical activity behaviours of overweight and obese pregnant women: a qualitative study. Midwifery 2017; 47:28-35.

49. Bauman A, Phongsavan P, Schoeppe S, Owen N. Physical activity measurement - a primer for health promotion. Promot Educ 2006; 13:92-103.

50. World Health Organization. Physical status: the use and interpretation of anthropometry. https://apps.who.int/iris/bitstream/han dle/10665/37003/WHO_TRS_854.pdf;jsessio nid $=869$ C $843 \mathrm{E} 273 \mathrm{FC} 356 \mathrm{C} 74 \mathrm{BE} 0 \mathrm{CA} 2 \mathrm{D} 8 \mathrm{AC} 3$ 9E? sequence $=1$ (accessed on 21/Abr/2019). 


\section{Resumo}

As intervenções durante o acompanhamento prénatal podem mitigar os desfechos negativos do sedentarismo e da dieta não saudável durante a gravidez. Os autores buscaram avaliar a efetividade de uma intervenção de promoção de dieta saudável e caminhadas no lazer durante o acompanhamento pré-natal, através de um estudo de intervenção pragmático, controlado, não-randomizado. Médicos e enfermeiros de todas as unidades da Estratégia Saúde da Família participaram da capacitação na promoção de caminhadas e diet saudável, como parte do acompanhamento pré-natal. O grupo da intervenção consistia em gestantes que receberam cuidados desses profissionais $(n=181)$. O grupo controle $(n=172)$ incluía as gestantes que recebiam os cuidados pré-natais usuais, nas unidades do modelo assistencial tradicional. Os dados eram coletados em cada trimestre da gestação. A dieta era investigada com um questionário de frequência alimentar, adaptado do Vigilância de Fatores de Risco e Proteção para Doenças Crônicas por Inquérito Telefônico (Vigitel). As caminhadas no lazer em uma semana típica eram avaliadas com perguntas do Physical Activity in Pregnancy Questionnaire. Houve efeitos positivos sobre o tempo de caminhada no segundo e terceiro trimestres da gestação e nas mulheres que atingiam 150 minutos semanais de caminhadas no terceiro trimestre. A intervenção reduziu o risco de gestantes consumirem refrigerantes e/ou biscoitos industrializados no terceiro trimestre. A intervenção no estilo de vida foi parcialmente efetiva, triplicando a proporção de gestantes que atingiam o tempo recomendado de caminhada e reduzindo pela metade a proporção de mulheres com alto consumo semanal de refrigerantes e biscoitos industrializados.

Gravidez; Conhecimentos, Atitudes e Práticas em Saúde; Alimentos, Dieta e Nutrição

\section{Resumen}

Las intervenciones durante el cuidado prenatal pueden mitigar los resultados negativos de un estilo de vida sedentario y una dieta insana $d u$ rante el embarazo. Nuestro objetivo fue evaluar la efectividad de una intervención que promovió una dieta saludable y los paseos en el tiempo de ocio, durante el cuidado prenatal, en un estudio pragmático, controlado y de intervención no aleatoria. Médicos y enfermeras de todas las unidades de cuidado de la Estrategia de Salud de la Familia, modelo de asistencia a la salud, participaron en la formación educacional para promover los paseos durante el tiempo de ocio, así como una dieta saludable durante las visitas de cuidado prenatal. Las mujeres embarazadas que recibieron asistencia de estos profesionales constituyeron el grupo de intervención $(n=181)$. El grupo de control $(n=172)$ incluyó a mujeres embarazadas, con una rutina de cuidados prenatales, en unidades de atención del modelo tradicional de asistencia en salud. Los datos fueron recabados en cada trimestre de embarazo. La dieta fue investigada usando el cuestionario de frecuencia de comidas adaptado del Vigilancia de Factores de Riesgo y Protección para Enfermedades Crónicas No Transmisibles por Entrevista Telefónica (Vigitel). Los paseos en el tiempo de ocio en una semana típica se evaluaron usando preguntas del Physical Activity in Pregnancy Questionnaire. Hubo efectos positivos por los paseos durante el tiempo de ocio en el segundo y tercer trimestre de embarazo, así como en las mujeres que alcanzaron 150 minutos por semana de paseos durante el tercer trimestre. La intervención redujo el riesgo de mujeres embarazadas que consumían refrescos y/o galletas empaquetadas en el tercer trimestre. La intervención en el estilo de vida fue parcialmente efectiva, triplicando la proporción de mujeres embarazadas que lograron el tiempo de paseos recomendados y redujeron a la mitad la proporción de mujeres que tuvieron una alta frecuencia semanal de consumo de refrescos $y$ galletas procesadas industrialmente.

Embarazo; Conocimientos, Actitudes y Práctica en Salud; Nutrición, Alimentación y Dieta
Submitted on $22 / \mathrm{Jan} / 2020$

Final version resubmitted on 15/May/2020

Approved on 17/Aug/2020 